\title{
Analysis Suppliers Selection of the Construction Raw Material in PT. Y Using VIKOR Method
}

\author{
Octavia Olga Citra Dewi ${ }^{1}$ and Erma Suryani ${ }^{2}$
}

\begin{abstract}
Improving supply chain management is one way to excel in competition. The selection of suppliers is an important part because the lack of proper supplier selection can lead to losses for the company. In its practice, the supplier selection process is more frequently based on a supplier that can provide the lowest price. This happens because the supplier selection process is considered to be at the operational level and not at the strategic level. The number of raw material suppliers on the construction project makes the developers be careful in choosing the material that is according to the developers' plans. All this time, the selection of suppliers involves many factors, sometimes a supplier has a good performance in terms of the delivery process, yet lacks in terms of quality compared to other suppliers and vice versa. Therefore, research must be done with a method that can take the factors, both the qualitative and quantitative, into consideration. This study is conducted to identify the factors of the selection of construction raw material suppliers and the support of alternative decision support in the selection of construction raw material suppliers. The purpose of this research is to identify the factors of the selection of raw material suppliers and the support of alternative decision in the selection of construction raw material suppliers. This research is expected to help the construction industry, especially in the city of Jember regarding the importance of knowing the factors of the selection of construction raw material suppliers and the decision of the selection of construction raw material suppliers especially if the selection of the construction raw material is in the power of the developer. The method used is the integration of AHP and Vikor using rough number. This research is expected to facilitate the process of selecting raw material suppliers and the selection of its alternatives.The results of this study gain the order of priority of 9 criteria and 23 sub-criteria. The recommended selection of suppliers based on its ranking on the sand suppliers is sand supplier P3, sand supplier P2, and sand supplier P1. Meanwhile, the ranking for the coral suppliers is coral supplier K3, then coral supplier K2, and lastly coral supplier $\mathrm{K} 1$.
\end{abstract}

Keywords-AHP, Rough Number, Supplier Selection, VIKOR.

\section{INTRODUCTION}

There are many factors that are considered by companies in the procurement process of goods and services, including the selection process of suppliers/contractors

${ }^{1}$ Octavia Olga Citra Dewi is with Departement of Management Technology Institut Teknologi Sepuluh Nopember, Indonesia. Email: octacd@gmail.com.

${ }^{2}$ Erma Suryani is with Departement of Information Systems, Institut Teknologi Sepuluh Nopember, Indonesia. Email: erma.suryani@gmail.com. (supplier/vendor). The selection of suppliers is one of the important and strategic activities on the part of procurement to achieve competitive advantage[1]-[3]. Effective and accurate supplier selection decision is an essential component for production and logistics management in many companies to enhance the competitiveness of companies[4], [5]. There are several methods in the procurement process of raw material on construction project such as the developer provides raw material specifications to the main contractor, then the main contractor procures raw material on request (Call of order)[6]. There is also a pattern of raw material procurement which is directly appointed by the developer (Supply by owner) as the supplier for the appointed main contractor[7]. Other than that, there is also a pattern of the material procurement that combines the two methods above. There is a certain raw material in which the supplier gets directly appointed by the developer (Supply by owner) and there is also a material in which the developer only provides the specifications of that material (Call of order).

This project is the construction of landed house with small scale and low difficulty level. The construction does not involve third parties (contractors). The developer prefers to use the method of supply by the owner in its procurement process of raw material.

The procurement process of raw material or what commonly referred to as the pattern of supply chain which involves many stakeholders from the beginning of production until the end of production. The characteristics of supply chain method can lead to coordination problems which potentially lead to waste if not regulated in proper management.

In its practice, the selection process of suppliers is more frequently based on a supplier who can provide the lowest price. Such thing happens due to the selection process of supplier which is considered to be at the operational level and not at the strategic level. The number of raw material suppliers in construction projects makes the developers very careful in choosing the material according to the developers' plans.

Previously, the selection of suppliers is rather difficult to do because a supplier has good ratings in the delivery process, but lacking in quality compared to other suppliers and vice versa. For that, the assessment method must be developed to make the selection of suppliers, especially for raw material suppliers, to be more structured. 
In this study, the AHP method and its integration with Vlse Kriterijumska Optimizacija I Kompromisno Resenje (VIKOR) and combined with rough number. In the process of criteria weighting, the AHP method is used and the alternative ranking uses the VIKOR method. Meanwhile rough number is used to increase the objectivity of expert assessment in decision-making.

\section{METHOD}

\section{A. Rough Number}

Due to the subjectivity and group characteristics of the design concept evaluation, how to aggregate individual judgments and priorities from group experts and manage the subjectivity among them become urgent tasks. In this paper, rough number is introduced to handle these problems. Inspired by rough set theory, rough number is first proposed by Zhai et al. [8] with the purpose of handling subjective judgments of customers and determining the boundary intervals. A rough number usually contains lower limit, upper limit and the rough boundary interval, which only depends on the original data. Thus it does not require any auxiliaryinformation and can better capture the experts' real perception and improve the objectivity of the decision making.

Suppose $\mathrm{U}$ is the universe which contains all the objects, $\mathrm{Y}$ is an arbitrary object of $\mathrm{U} ; \mathrm{R}$ is a set of $\mathrm{t}$ classes $\left(G_{1}, G_{2}, \ldots, G_{t}\right)$ that cover all the objects in $\mathrm{U} ; R=$ $\left\{G_{1}, G_{2}, \ldots, G_{t}\right\}$ If these classes are ordered $G_{1}<G_{2}<\ldots<$ $G_{t}$, then $\forall Y \in U ; G q \in R, 1 \leq q \leq t$, the lower approximation $\left(\underline{\operatorname{Apr}}\left(G_{q}\right)\right)$, upper approximation $\left(\overline{\operatorname{Apr}}\left(G_{q}\right)\right)$ and boundary region $\left(B n d\left(G_{q}\right)\right)$ of class $G q$ are defined as:

$$
\begin{aligned}
\operatorname{Apr}\left(G_{q}\right)= & \cup\left\{Y \in U / R(Y) \leq G_{q}\right\} \\
\overline{\operatorname{Apr}}\left(G_{q}\right)= & \cup\left\{Y \in \frac{U}{R(Y)} \leq G_{q}\right\} \\
\operatorname{Bnd}\left(G_{q}\right)= & \cup\left\{Y \in \frac{U}{R(Y)} \neq G_{q}\right\} \\
= & \left\{Y \in U / R(Y)>G_{q}\right\} \\
& \cup\left\{Y \in U / R(Y)<G_{q}\right\}
\end{aligned}
$$

Then $G_{q}$ can be represented by a rough number $\left(R N\left(G_{q}\right)\right)$, which is determined by its corresponding lower limiti $\left(\underline{\operatorname{Lim}}\left(G_{q}\right)\right)$ and upper limit $\left(\overline{\operatorname{Lim}}\left(G_{q}\right)\right)$, where :

$$
\begin{aligned}
& \underline{\operatorname{Lim}}\left(G_{q}\right)=\frac{1}{M_{l}} \sum R(Y) \mid Y \in \underline{A p r}\left(G_{q}\right) \\
& \overline{\operatorname{Lim}}\left(G_{q}\right)=1 / M_{U} \sum R(Y) \mid Y \in \overline{\operatorname{Apr}}\left(G_{q}\right) \\
& \operatorname{RN}\left(G_{q}\right)=\left\lceil\underline{\operatorname{Lim}}\left(G_{q}\right), \overline{\operatorname{Lim}}\left(G_{q}\right)\right\rfloor
\end{aligned}
$$

where $M_{L}, M_{u}$ are the number of objects that contained in $\underline{\operatorname{Apr}}\left(G_{q}\right)$ and $\overline{\operatorname{Apr}}\left(G_{q}\right)$, respectively.
The lower limit and upper limit denote the mean value of elements included in its corresponding lower approximation and upper approximation, respectively. Their difference is defined as rough boundary interval $\left(\operatorname{IRBnd}\left(G_{q}\right)\right)$ :

$$
\left(\operatorname{IRBnd}\left(G_{q}\right)\right)=\overline{\operatorname{Lim}}\left(G_{q}\right)-\underline{\operatorname{Lim}}\left(G_{q}\right)
$$

The rough boundary interval denotes the vagueness of $G q$, where a larger one means more vague while a smaller one denotes a better precise. Then the subjective information can be denoted by rough number.

Take a data set $U=\{3,5,7,3,7\}$ for example, it has three classes and $R=\left\{G_{1}, G_{2}, G_{3}\right\}=\{3,5,7\}$. Take $G_{2}$ to explain the definition of the rough number, according to Eqs (1) (3):

$$
\begin{aligned}
& \operatorname{Apr}(5)=\cup\left\{Y \in \frac{U}{R(Y)} \leq 5\right\}=\{3,5,3\} \\
& \overline{A p r}(5)=\cup\left\{Y \in \frac{U}{R(Y)} \geq 5\right\}=\{5,7,7\} \\
& \operatorname{Bnd}(5)=\cup\left\{Y \in \frac{U}{R(Y)} \neq 5\right\}=\{3,7,3,7\}
\end{aligned}
$$

Therefore, the corresponding rough number of $G_{2}$ is calculated by Eqs. (4) - (6):

$$
\begin{aligned}
\underline{\operatorname{Lim}}(5)=\frac{1}{M_{l}} \sum R(Y) \mid Y \in \underline{\operatorname{Apr}}(5) \\
=\frac{1}{3}(3+5+3)=3.67 \\
\begin{aligned}
\underline{\operatorname{Lim}}(5)=\frac{1}{M_{U}} \sum R(Y) \mid Y \in \underline{A p r}(5) \\
=\frac{1}{3}(5+7+7)=6.33
\end{aligned} \\
R N(5)=\lceil\underline{\operatorname{Lim}}(5), \overline{\operatorname{Lim}}(5)\rfloor=\lceil 3.67,6.33\rceil
\end{aligned}
$$

The rough boundary interval of $G_{2}$ is defined as :

$$
\operatorname{IRBnd}(5)=\overline{\operatorname{Lim}}(5)-\underline{\operatorname{Lim}}(5)=2.66
$$

Finally, the element ' 5 ' in $U$ is represented by a rough numberIRBnd $(5)=\lceil 3.67,6.33\rfloor$. Similarly, other elements in $U$ are determined in the same way.

Because of the similarity with interval number, the arithmetic rules of interval number can also be used in rough number [9]. Suppose $R N(\propto)=[\underline{\operatorname{Lim}}(\propto), \overline{\operatorname{Lim}}(\propto)\rceil$ and $R N(\beta)=[\underline{\operatorname{Lim}}(\beta), \overline{\operatorname{Lim}}(\beta)\rceil$ are two rough numbers, $\mu$ is a nonzero constant, then:

$$
\begin{aligned}
& R N(\alpha) \times \mu=\lceil\underline{\operatorname{Lim}}(\propto), \overline{\operatorname{Lim}}(\propto)\rfloor \times \mu= \\
& \qquad \mu \times \underline{\operatorname{Lim}}(\alpha), \mu \times \overline{\operatorname{Lim}} \\
& R N(\alpha)+R N(\beta)=\lceil\underline{\operatorname{Lim}}(\propto), \overline{\operatorname{Lim}}(\propto)\rceil \\
& +\lceil\underline{\operatorname{Lim}}(\beta), \overline{\operatorname{Lim}}(\beta)\rfloor
\end{aligned}
$$




$$
\begin{aligned}
& =\lceil\underline{\operatorname{Lim}}(\alpha)+\overline{\operatorname{Lim}}(\beta), \underline{\operatorname{Lim}}(\alpha), \overline{\operatorname{Lim}}(\beta)\rfloor \\
& R N(\alpha) \times R N(\beta)=\lfloor\underline{\operatorname{Lim}}(\alpha), \overline{\operatorname{Lim}}(\alpha)\rfloor \\
& \times\lfloor\underline{\operatorname{Lim}}(\beta), \overline{\operatorname{Lim}}(\beta)\rfloor \\
& =\lceil\underline{\operatorname{Lim}}(\alpha) \times \overline{\operatorname{Lim}}(\alpha), \underline{\operatorname{Lim}}(\alpha) \times \overline{\operatorname{Lim}}(\beta)\rfloor
\end{aligned}
$$

\section{B. VIKOR}

VIKOR (Serbian name: VIseKriterijumska Optimizacija I Kompromisno Resenje), also known as compromise ranking method, is an effective tool in MCDM. It is developed from the Lp-metric in compromise programming:

$$
\begin{aligned}
& L_{p, i}=\left\{\sum_{j=1}^{m}\left[w_{j}\left(f_{j}^{*}-f_{i j}\right) /\left(f_{j}^{*}-f_{j}^{-}\right)\right]^{p}\right\}^{1 / p} \\
& 1 \leq p \leq \infty ; i=1,2, \ldots, n
\end{aligned}
$$

In VIKOR, L1; (expressed as Si) and L1;i (expressed as $\mathrm{Ri})$ are used to formulate ranking measure. The final compromise solution is the one with a maximum group utility (min $\mathrm{Si}$ ) of the majority, and a minimum of individual regret $(\min \mathrm{Ri})$ of the opponent. It is a feasible solution which is the closest to the ideal[10].

VIKOR is particularly powerful under such environment where the decision maker is unable, or does not know how to express his preference at the early stage of product development[11]. Furthermore, it has been combined with other methods including fuzzy sets, interval numbers and outranking methods to enhance its performance[12], [13]. Due to its unique superiority, VIKOR has been widely used in various decision-making areas, such as material selection, robot selection and supplier selection[12], [14], [15].

Among various decision-making techniques, AHP is widely used in the determination of relative importance while VIKOR is a powerful alternative evaluation method. The rough number is a good choice to manipulate the subjectivity and aggregate individual judgments and priorities under group decision-making environment. Thus these three methods can be combined to integrate the merit of AHP in hierarchy evaluation, the superiority of rough number in manipulating vagueness and the virtue of VIKOR in modeling MCDM to improve the objectivity of decision making.

\section{RESULTS AND DISCUSSION}

\section{A. Data Collection Method}

1) Identifying criteria for the selection of suppliers by conducting a literature study, observations, and interviews. After that, the supplier selection criteria are formulated.

2) With questionnaires by doing pairwise comparation using a scale of 1-9 and with questionnaires by doing supplier assessment using Likert scale of 1-4.

\section{B. Framework Method}

In general, the steps of this study are divided into two parts.The determination of relative importance of evaluation criterion and the alternative ranking. In order to eliminate the bias of the evaluation process, the two phases must be taken into consideration simultaneously. For the purpose of handling the vagueness and subjectivity in product design evaluation, this paper proposes an integrated approach by introducing rough number into AHP and VIKOR. Rough number is adopted and combined with AHP to calculate relative importance. Then the paper presents a rough VIKOR to evaluate design concept alternatives. By combining with rough AHP and rough VIKOR, both relative importance of each criterion and final alternative ranking are determined without any auxiliary information. Thus, the proposed method can effectively reflect the decision makers' true perception and strengthen the objectivity of design concept evaluation. The framework of the proposed method is depicted in Fig. 1.

\section{AHP (Analytical Hierarchy Process) for Criteria Weighting}

AHP is the most popular method in the decision-making, especially in the criteria weighting. AHP is able to measure the consistency of respondents or experts' preference, to cope with the decision-making with tangible and nontangible criteria, to manage the decision-making with the criteria that are based on subjective judgments.

Step 1 : Identify the evaluation objective, criteria and alternatives. Construct a hierarchical structure with the evaluation objective at the top layer, criteria at the middle and alternatives at the bottom.

Step 2: Conduct AHP survey and construct a group of pair-wise comparison matrices. The pair-wise comparison matrix of the eth expert is described as:

$$
B=\left[\begin{array}{ccc}
1 & \ldots & x_{1 m} \\
x_{21} & 1 \ldots & x_{2 m} \\
x_{m 1} & x_{m 2} \ldots & 1
\end{array}\right]
$$

where $x_{g h}^{e}(1 \leq g \leq m \leq h \leq m, 1 \leq e \leq s)$ is the relative importance of criterion $\mathrm{g}$ on criterion $\mathrm{h}$ given by responden, $\mathrm{m}$ is the number of criteria, $\mathrm{s}$ is the number of responden.

Calculate the maximum eigenvalue $\lambda_{\max }^{e} \max$ of $B_{e}$, then compute the consistency index $C I=\left(\lambda_{\max }^{e}-\right.$ $m) /(m-1)$

Determine the random consistency index (RI) according to $\mathrm{m}$. Compute the consistency ratio $\mathrm{CR} 1 / 4 \mathrm{CI}=\mathrm{RI}$. Conduct consistency test. If $\mathrm{CR}<0.1$, the comparison matrix is acceptable. Otherwise, responden judgments should be adjusted until $\mathrm{CR}<0.1$.

Then integrated comparation matrix $B$ is built as: 
The $1^{\text {st }}$ International Conference on Business and Management of Technology (IConBMT)

August 3rd 2019, Institut Teknologi Sepuluh Nopember, Surabaya, Indonesia

$$
B=\left[\begin{array}{ccc}
1 & \ldots & x_{1 m} \\
x_{21} & 1 \ldots & x_{2 m} \\
x_{m 1} & x_{m 2} \ldots & 1
\end{array}\right]
$$

Where $x_{g h}=\left\{x_{g h}^{1}, x_{g h}^{2}, \ldots x_{g h}^{5}\right\}, x_{g h}$ is the sequence of relative importances of criterion $\mathrm{g}$ on criterion $\mathrm{h}$.

Step 3: Construct a rough comparison matrix.

Translate the element $x_{g h}^{e}$ in B into rough number $R N$ ( $\left.x_{g h}^{e}\right)$ using eqs. (1)-(6):

$$
R N\left(x_{g h}^{e}\right)=\left\lceil x_{g h}^{e L}, x_{g h}^{e U}\right\rfloor
$$

Where $x_{g h}^{e L}$ is the lower limit of $R N\left(x_{g h}^{e L}\right)$ while $x_{g h}^{e L}$ is the upper limit.

Then the rough sequence $R N\left(x_{g h}^{e L}\right)$ is represented as:

$$
R N\left(\tilde{x}_{g h}\right)=\left\{\left[x_{g h}^{1 L}, x_{g h}^{1 U}\right],\left[x_{g h}^{2 L}, x_{g h}^{2 U} \mid, \ldots,\left[x_{g h}^{s L}, x_{g h}^{s U} \mid\right\}\right.\right.
$$

Is further translated into an avarage rough number $R N\left(x_{g h}\right)$ by rough arithmetic eqs (8)-(10)

$$
\begin{aligned}
& R N\left(x_{g h}\right)=\left[x_{g h}^{L}, x_{g h}^{U}\right\rfloor \\
& x_{g h}^{L}=\frac{x_{g h}^{1 L}+x_{g h}^{2 L}+\cdots+x_{g h}^{s L}}{s} \\
& x_{g h}^{U}=\frac{x_{g h}^{1 U}+x_{g h}^{2 U}+\cdots+x_{g h}^{s U}}{s}
\end{aligned}
$$

where $\left(x_{g h}^{L}\right)$ is the lower limit of $R N\left(x_{g h}^{e L}\right)$ and $\left(x_{g h}^{U}\right)$ is the upper limit.

Then the rough comparison matrix $\mathrm{M}$ is formed as:

$$
M=\left[\begin{array}{cccc}
\lceil 1,1\rfloor & \left\lceil x_{12}^{L}, x_{12}^{U}\right\rfloor & \cdots & \left\lceil x_{1 m}^{L}, x_{1 m}^{U}\right\rfloor \\
\left\lceil x_{21}^{L}, x_{21}^{U}\right\rfloor & \lceil 1,1\rfloor & \cdots & \left\lceil x_{2 m}^{L}, x_{2 m}^{U}\right\rfloor \\
\vdots & \vdots & \ddots & \vdots \\
\left\lceil x_{m 1}^{L}, x_{m 1}^{U}\right\rfloor & \left\lceil x_{m 2}^{L}, x_{m 2}^{U}\right\rfloor & \cdots & \lceil 1,1\rfloor
\end{array}\right]
$$

Step 4 : calculate the rough weight of each criterion and subcriterion.

$$
\begin{aligned}
& w_{g}=\left\lceil\sqrt[m]{\prod_{h-1}^{m} x_{g h}^{L}}, \sqrt[m]{\prod_{h-1}^{m} x_{g h}^{U}}\right\rfloor \\
& w_{g}^{\prime}=w_{g} / \max \left(w_{g}^{U}\right)
\end{aligned}
$$

where $w_{g}^{\prime}$ is the normalization form.

\section{VIKOR for Alternatives Evaluation}

Based on the relative importance of each criterion calculated by rough AHP, rough VIKOR is proposed to aggregate individual priorities and evaluate design concept alternatives, which is conducted as follows.
Step 1: Construct a group of decision matrices and translate them into a rough decision matrix $\mathrm{D}$ according to Eqs. (1)-(10):

$$
D=\left[\begin{array}{cccc}
{\left[f_{11}^{L}, f_{11}^{U}\right]} & {\left[f_{12}^{L}, f_{12}^{U}\right]} & \cdots & {\left[f_{1 m}^{L}, f_{1 m}^{U}\right]} \\
{\left[f_{21}^{L}, f_{21}^{U}\right]} & {\left[f_{22}^{L}, f_{22}^{U}\right]} & \cdots & {\left[f_{2 m}^{L}, f_{2 m}^{U} \mid\right.} \\
\vdots & \vdots & \ddots & \vdots \\
{\left[f_{n 1}^{L}, f_{n 1}^{U}\right]} & {\left[f_{n 2}^{L}, f_{n 2}^{U}\right]} & \cdots & {\left[f_{n m}^{L}, f_{n m}^{U}\right]}
\end{array}\right]
$$

Where is the evaluation value of criterion $\mathrm{j}$ for alternative $i$ given by expert e, the construction of matrix $\mathrm{D}$ is similar as $\mathrm{M}$

Step 2: Identify the best value $\mathrm{f}_{-}$and the worst value $\mathrm{f}_{-}$ $\mathrm{j}$ of each criterion in D. For the benefit criterion which belongs to the "larger-the-better" category: $f_{-} j^{1 / 4}$ maxif Uij ; f j j $1 / 4$ minif Lij; For the cost criterion which belongs to the "smaller-the-better" category:f $\_j$ 1/4 minif Lij; $f_{-} j$ $1 / 4$ maxif Uij ; that is

$$
\begin{aligned}
& f_{j}^{*}=\left\{\left(\max _{i} f_{i j}^{U} j j \in B\right) \text { or }\left(\min _{i} f_{i j}^{L} \mid j \in C\right)\right\} \\
& f_{j}=\left\{\left(\min _{i} f_{i j}^{L} \mid j \in B\right) \text { or }\left(\max _{i} f_{i j}^{U} \mid j \in C\right)\right\}
\end{aligned}
$$

where $\mathrm{B}$ is associated with the benefit criterion while $\mathrm{C}$ is associatedwith the cost criterion.

Step 3: Calculate the values

$S_{i}^{L}=\sum_{j \in B} w_{j}^{L}\left(f_{j}^{*}-f_{i j}^{U}\right) /\left(f_{j}^{*}-f_{j}^{-}\right)+\sum_{j \in C} w_{j}^{L}\left(f_{i j}^{L}-f_{j}\right) /\left(f_{j}^{-}-f_{j}\right)$

$S_{i}^{U}=\sum_{j \in B} w_{j}^{U}\left(f_{j}^{*}-f_{i j}^{L}\right) /\left(f_{j}^{*}-f_{j}^{-}\right)+\sum_{j \in C} w_{j}^{U}\left(f_{i j}^{u}-f_{j}\right) /\left(f_{j}-f_{j}^{*}\right)$

$R_{i}^{L}=\max _{j}\left\{\begin{array}{l}w_{j}^{L}\left(f_{j}^{*}-f_{i j}^{U}\right) /\left(f_{j}^{*}-f_{j}\right) \mid j \in B \\ w_{j}^{L}\left(f_{i j}^{L}-f_{j}^{*}\right) /\left(f_{j}^{-}-f_{j}\right) \mid j \in C\end{array}\right.$

$R_{i}^{U}=\max _{j}\left\{\begin{array}{l}w_{j}^{U}\left(f_{j}^{*}-f_{i j}^{L}\right) /\left(f_{j}^{*}-f_{j}^{-}\right) \mid j \in B \\ w_{j}^{U}\left(f_{i j}^{U}-f_{j}^{*}\right) /\left(f_{j}^{-}-f_{j}^{*}\right) \mid j \in C\end{array}\right.$

Step 4: Calculate the values

$Q_{i}^{L}=v\left(S_{i}^{L}-S^{*}\right) /\left(S^{-}-S^{*}\right)+(1-v)\left(R_{i}^{L}-R^{*}\right) /\left(R^{-}-R^{*}\right)$

$Q_{i}^{U}=v\left(S_{i}^{U}-S^{*}\right) /\left(S^{-}-S^{*}\right)+(1-v)\left(R_{i}^{U}-R^{*}\right) /\left(R^{-}-R^{*}\right)$

Step 5: Rank the alternatives in ascending order, on the basis of $\mathrm{S} ; \mathrm{R} ; \mathrm{Q}$. Then three arrangements are obtained

Step 6: Propose the alternative Aa as a compromise solution, which is the best ranked with respect to $\mathrm{Q}$ (minimum), if the following two conditions are satisfied:

C1: Acceptable advantage:

$\sqrt{\frac{1}{2}\left[\left(Q^{U}\left(A_{b}\right)-Q^{U}\left(A_{a}\right)\right)^{2}+\left(Q^{L}\left(A_{b}\right)-Q^{L}\left(A_{a}\right)^{2}\right]\right.} \geqslant 1 /(n-1)$

$Q^{u}:$ Nilai indeks VIKOR upper 
$Q^{L}$ : Nilai indeks VIKOR lower

$A_{a}$ : Pemasok rangking pertama

$A_{b}$ : Pemasok rangking terakhir

C2: Acceptable stability in decision-making:

Aa must also be the best ranked with respect to $\mathrm{S}$ or/and

R. This compromise solution is stable in decision-making process. When $\mathrm{v}>0: 5$,

By combining with rough AHP and rough VIKOR, the design concept evaluation is conducted and the subjectivity is effectively addressed.

\section{RESUlt AND DisCUSSION}

\section{A. Criteria and Subcriteria Identification}

Observations, interviews, and questionnaires are conducted to commissioner, director, and field supervisor. This selection of respondents are based on the consideration that these respondents are the people who know the entire project, as the decision maker. Afterward, three respondents are obtained which can be seen in Table 1.

TABLE 1.

RESPONDENT LIST

\begin{tabular}{ccc}
\hline \hline Respondent & Position & Commissioner \\
\hline Respondent 1 & Commissioner & 1 \\
Respondent 2 & Director & 1 \\
Respondent 3 & Field Supervisor & 1 \\
\hline \hline
\end{tabular}

The identification of criteria is based on the 23 criteria by Dickson[16], Wardhani[17], Bilal and Yani[18]. The questionnaire results obtain 9 criteria and 23 sub-criteria which can be seen in Table 2 .

\section{B. Data Collection Results}

\section{Criteria and Subcriteria Weighting}

Step 1: Create a pairwise comparison based on the respondent assessment of the questionnaire results as seen at Table 3.

Step 2: Change the comparison matrix into rough number of comparison matrix as seen at Table 4 .

Step 3: Calculate the weight of criteria and sub-criteria. As seen at Table 5- Table 14.

Step 4: Check the consistency of the pairwise comparison matrix as seen at Table 15.

\section{Suppliers Ranking}

With the steps as follow:

Step 1: Create rough matrix decisions based on the assessment questionnaire of raw material suppliers.

Step 2: Calculate the index value of rough VIKOR.

Step 3: Perform suppliers ranking based on the index of rough VIKOR. As seen at Table 16 and table 17

Step 4: The examination of acceptable advantage of the ranking results of the rough VIKOR index.

The calculation results of acceptable advantage obtained a value of 0.5272 (rough sand VIKOR) and 0.5711 (rough coral VIKOR). The two obtained values are already greater than 0.5 , so it can be concluded that the acceptable advantage condition of rough VIKOR calculation can be fulfilled.

\section{CONCLUSION}

This study has defined the criteria for selecting raw material suppliers in accordance with the desires of the developer. Based on the 9 criteria along with its 23 subcriteria, the weighting which indicates the priority level and needs of each criteria and sub-criteria has been obtained.

Based on the ranking which uses rough VIKOR, the order of sand raw material suppliers according to its ranking is sand supplier P3, sand supplier P2, sand supplier $\mathrm{P} 1$. The ranking of coral raw material suppliers is coral supplier K3, coral supplier K2, coral supplier K1.

TABLE 2.

SELECTION SUPPLIERS CRITERIA AND SUBCRITERIA

\begin{tabular}{llll}
\hline \hline No & Criteria & & \multicolumn{1}{c}{ Sub-criteria } \\
\hline 1 & Cost & K1 & Payment method \\
& K2 & Bid price \\
\hline 2 & Delivery & K3 & Delivery time \\
& K4 & Transportation costs \\
& K5 & Delivery Frequency \\
& K6 & Types of Transportation Mode \\
& K7 & Shipping Amount \\
\hline 3 & Quality & K8 & Completeness of Checking Documents \\
& K9 & Defect Rate \\
& K10 & Ability to Provide Consistent Quality \\
& K11 & Facility of Addition or Reduction in Order Amount \\
& K12 & Facility of Changing Delivery Time \\
\hline 4 & K13 & The Facility of Defective Products Replacement \\
& Responsiveness & Speed in Responding to Customer Desires \\
\hline 5 & &
\end{tabular}


The $1^{\text {st }}$ International Conference on Business and Management of Technology (IConBMT)

August 3rd 2019, Institut Teknologi Sepuluh Nopember, Surabaya, Indonesia

\begin{tabular}{llll}
\hline 6 & Warranties \& Claim Policies & K15 & Providing a warranty or guarantee for goods \\
& & K16 & Ability to Provide Assistance in an Emergency \\
\hline 7 & Performance History & K17 & Ability to fulfill in number of orders \\
& K18 & Ability to maintain contract agreements \\
& K19 & Ability to fulfill determined schedules \\
\hline 8 & Communication System & K20 & Types of used communication media \\
& & K21 & Consistency level for information exchange \\
\hline 9 & Management \& Organization & K22 & Completeness of company documents \\
& & K23 & Completeness of goods offer document \\
\hline \hline
\end{tabular}

TABLE 3.

\begin{tabular}{l|cccccccccc|}
\multicolumn{10}{c}{ PAIR-WISE MATRIX OF SUPPLIERS SELECTION CRITERIA } \\
$\mathrm{K} 1$ & $1,1,1$ & $3,1,3$ & $1,1,3$ & $2,3,4$ & $1,5,4$ & $1,4,4$ & $3,4,4$ & $7,5,4$ & $7,6,7$ & $7,6,7$ \\
$\mathrm{~K} 2$ & $1 / 3,1,1 / 3$ & $1,1,1$ & $1 / 3,1 / 2,1 / 3$ & $5,4,1$ & $4,2,1$ & $3,4,3$ & $7,3,3$ & $7,4,5$ & $6,4,6$ & $5,4,6$ \\
$\mathrm{~K} 3$ & $1,1,1 / 3$ & $3,2,3$ & $1,1,1$ & $8,6,4$ & $8,4,3$ & $8,4,3$ & $9,4,3$ & $9,4,7$ & $8,3,8$ & $8,3,8$ \\
$\mathrm{~K} 4$ & $1 / 2,1 / 3,1 / 4$ & $1 / 5,1 / 4,1$ & $1 / 8,1 / 6,1 / 4$ & $1,1,1$ & $1,1,1$ & $1,1,2$ & $1,1,3$ & $5,7,4$ & $4,6,3$ & $5,5,5$ \\
$\mathrm{~K} 5$ & $1,1 / 5,1 / 4$ & $1 / 4,1 / 2,1$ & $1 / 8,1 / 4,1 / 3$ & $1,1,1$ & $1,1,1$ & $2,1,2$ & $2,2,3$ & $5,3,5$ & $1,3,5$ & $3,5,5$ \\
$\mathrm{~K} 6$ & $1,1 / 4,1 / 4$ & $1 / 3,1 / 4,1 / 3$ & $1 / 8,1 / 4,1 / 3$ & $1,1,1 / 2$ & $1 / 2,1,1 / 2$ & $1,1,1$ & $3,4,1 / 2$ & $4,4,2$ & $3,4,3$ & $5,6,2$ \\
$\mathrm{~K} 7$ & $1 / 3,1 / 4,1 / 4$ & $1 / 7,1 / 3,1 / 3$ & $1 / 9,1 / 4,1 / 3$ & $1,1,1 / 3$ & $1 / 2,1 / 2,1 / 3$ & $1 / 3,1 / 4,2$ & $1,1,1$ & $1,5,4$ & $1 / 2,3,2$ & $1 / 2,2.2$ \\
$\mathrm{~K} 8$ & $1 / 7,1 / 5,1 / 4$ & $1 / 7,1 / 4,1 / 5$ & $1 / 9,1 / 4,1 / 7$ & $1 / 5,1 / 7,1 / 4$ & $1 / 5,1 / 3,1 / 5$ & $1 / 4,1 / 4,1 / 2$ & $1,1 / 5,1 / 4$ & $1,1,1$ & $1 / 2,3,4$ & $1 / 2,2,2$ \\
$\mathrm{~K} 9$ & $1 / 7,1 / 6,1 / 7$ & $1 / 6,1 / 4,1 / 6$ & $1 / 8,1 / 3,1 / 8$ & $1 / 4,1 / 6,1 / 3$ & $1,1 / 3,1 / 5$ & $1 / 3,1 / 4,1 / 3$ & $2,1 / 3,1 / 2$ & $2,1 / 3,1 / 4$ & $1,1,1$ & $2,2,2$ \\
$\mathrm{~K} 10$ & $1 / 7,1 / 6,1 / 7$ & $1 / 5,1 / 4,1 / 6$ & $1 / 8,1 / 3,1 / 8$ & $1 / 5,1 / 5,1 / 5$ & $1 / 3,1 / 5,1 / 5$ & $1 / 5,1 / 6,1 / 2$ & $2,1 / 2,1 / 2$ & $2,1 / 2,1 / 2$ & $1 / 2,1 / 2,1 / 2$ & $1,1,1$
\end{tabular}

TABLE V.

\begin{tabular}{l|ccccccccc|}
\multicolumn{7}{c}{ PAIR-WiSE CRITERIA ROUGH NuMBER MATRIX } \\
K1 & {$[1,1]$} & {$[1.89,2.78]$} & {$[1.22,2.11]$} & {$[2.50,3.50]$} & {$[2.28,4.28]$} & {$[2.33,3.67]$} & {$[3.44,3.89]$} & {$[4.61,6.11]$} & {$[6.44,6.89]$} \\
K2 & {$[0.36]$} & {$[1,1]$} & {$[0.35,0.43]$} & {$[2.28,4.28]$} & {$[1.61,3.11]$} & {$[3.11,3.56]$} & {$[3.44,5.22]$} & {$[4.61,6.11]$} & {$[4.50,5.50]$} \\
K3 & {$[0.47,0.82]$} & {$[2.35]$} & {$[1,1]$} & {$[5.00,7.00]$} & {$[3.83,6.33]$} & {$[3.83,6.33]$} & {$[3.94,6.94]$} & {$[5.39,7.89]$} & {$[5.22,7.44]$} \\
K4 & {$[0.29,0.40]$} & {$[0.23,0.44]$} & {$[0.14,0.20]$} & {$[1,1]$} & {$[1,1]$} & {$[1.33,1.56]$} & {$[1.22,2.11]$} & {$[4.61,6.11]$} & {$[5,5]$} \\
K5 & {$[0.23,0.44]$} & {$[0.32,0.62]$} & {$[0.16,0.26]$} & {$[1,1]$} & {$[1,1]$} & {$[1.44,1.89]$} & {$[2.11,2.56]$} & {$[3.89,4.78]$} & {$[3.89,4.78]$} \\
K6 & {$[0.27,0.43]$} & {$[0.28,0.32]$} & {$[0.16,0.26]$} & {$[0.64,0.75]$} & {$[0.53,0.69]$} & {$[1,1]$} & {$[1.58,3.33]$} & {$[2.89,3.78]$} & {$[3.28,5.28]$} \\
K7 & {$[0.26,0.29]$} & {$[0.19,0.29]$} & {$[0.14,0.25]$} & {$[0.47,0.82]$} & {$[0.39,0.47]$} & {$[0.30,0.63]$} & {$[1,1]$} & {$[2.28,4.28]$} & {$[1.17,1.83]$} \\
K8 & {$[0.16,0.22]$} & {$[0.16,0.22]$} & {$[0.13,0.19]$} & {$[0.16,0.22]$} & {$[0.21,0.26]$} & {$[0.26,0.35]$} & {$[0.23,0.44]$} & {$[1,1]$} & {$[1.17,1.83]$} \\
K9 & {$[0.15,0.16]$} & {$[0.18,0.22]$} & {$[0.13,0.19]$} & {$[0.20,0.20]$} & {$[0.21,0.26]$} & {$[0.19,0.31]$} & {$[0.55,0.86]$} & {$[0.55,0.86]$} & {$[1,1]$}
\end{tabular}

TABLE 5 .

CRITERIA WEIGHT

\begin{tabular}{|c|c|c|c|}
\hline \multirow{2}{*}{ Criteria } & \multicolumn{2}{|c|}{ Weight } & \multirow{2}{*}{ Priority } \\
\hline & Lower & Upper & \\
\hline Quality & 0.688 & 1 & 1 \\
\hline Cost & 0.632 & 0.844 & 2 \\
\hline Delivery & 0.437 & 0.595 & 3 \\
\hline Responsiveness & 0.236 & 0.331 & 4 \\
\hline Flexibility & 0.24 & 0.313 & 5 \\
\hline Warranty \& Claim Policies & 0.199 & 0.272 & 6 \\
\hline Performance History & 0.12 & 0.186 & 7 \\
\hline Communication System & 0.076 & 0.11 & 8 \\
\hline Management \& Organization & 0.068 & 0.085 & 9 \\
\hline
\end{tabular}

TABLE 6.

THE PRIORITY WeIGHT OF QUALITY SUB-CRITERIA

\begin{tabular}{lccc}
\hline \hline \multirow{2}{*}{ Quality sub-criteria } & \multicolumn{2}{c}{ Weight } & \multirow{2}{*}{ Priority } \\
\cline { 2 - 3 } & Lower & Upper & \\
\hline Ability to Provide Consistent Quality & 0.573 & 1.000 & 1 \\
Completeness of Checking Documents & 0.350 & 0.570 & 2 \\
Defect Rate & 0.285 & 0.559 & 3 \\
\hline \hline
\end{tabular}

TABLE 7.

THE PRIORITY WeIGHT OF COST SUB-CRITERIA

\begin{tabular}{|c|c|c|c|}
\hline \multirow{2}{*}{ Cost sub-criteria } & \multicolumn{2}{|c|}{ Weight } & \multirow{2}{*}{ Priority } \\
\hline & Lower & Upper & \\
\hline Payment method & 0.534 & 0.844 & 1 \\
\hline Bid price & 0.089 & 0.143 & 2 \\
\hline
\end{tabular}


The $1^{\text {st }}$ International Conference on Business and Management of Technology (IConBMT) August 3rd 2019, Institut Teknologi Sepuluh Nopember, Surabaya, Indonesia

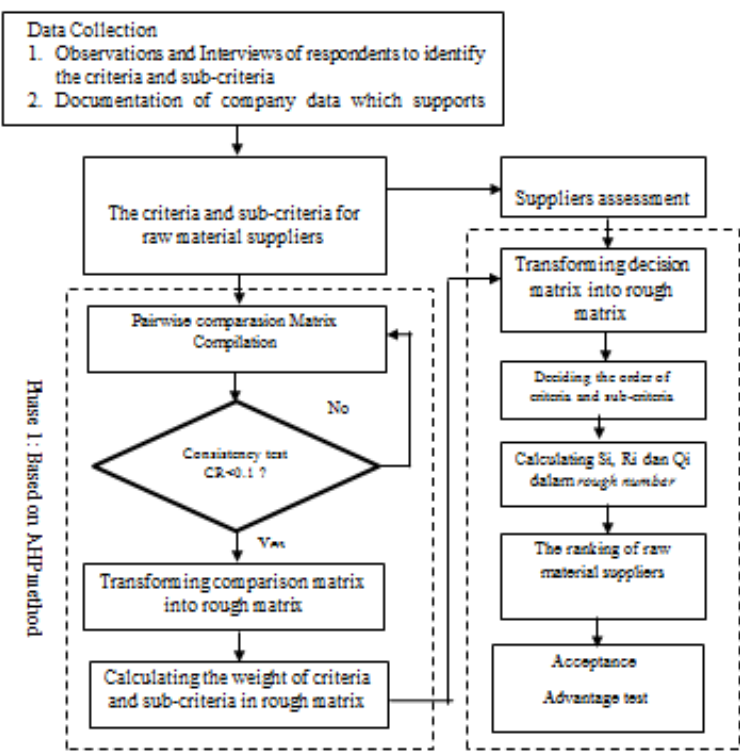

Figure 1. Research Flowchart

TABLE 8.

THE PRIORITY WEIGHT OF DELIVERY SUB-CRITERIA

\begin{tabular}{|c|c|c|c|}
\hline \multirow{2}{*}{ Delivery sub-criteria } & \multicolumn{2}{|c|}{ Weight } & \multirow{2}{*}{ Priority } \\
\hline & Lower & Upper & \\
\hline Delivery time & 0.263 & 0.595 & 1 \\
\hline Transportation costs & 0.195 & 0.403 & 2 \\
\hline Delivery Frequency & 0.117 & 0.274 & 3 \\
\hline Shipping Amount & 0.087 & 0.196 & 4 \\
\hline Types of Transportation Mode & 0.055 & 0.117 & 5 \\
\hline
\end{tabular}

TABLE 9.

THE PRIORITY WEIGHT OF RESPONSIVENESS SUB-CRITERIA

\begin{tabular}{|c|c|c|c|}
\hline \multirow{2}{*}{ Responsiveness sub-criteria } & \multicolumn{2}{|c|}{ Weight } & \multirow{2}{*}{ Priority } \\
\hline & Lower & Upper & \\
\hline Speed in Responding to Customer Desires & 0.163 & 0.331 & 1 \\
\hline $\begin{array}{l}\text { The Facility of Defective Products } \\
\text { Replacement }\end{array}$ & 0.071 & 0.144 & 2 \\
\hline
\end{tabular}

TABLE 10.

THE PRIORITY WEIGHT OF FLEXIBILITY SUB-CRITERIA

\begin{tabular}{lccc}
\hline \hline \multirow{2}{*}{ Flexibility sub-criteria } & \multicolumn{2}{c}{ Weight } & \multirow{2}{*}{ Priority } \\
\cline { 2 - 3 } & Lower & Upper & \\
\hline $\begin{array}{l}\text { Facility of Addition or Reduction in } \\
\text { Order Amount }\end{array}$ & 0.186 & 0.313 & 1 \\
Facility of Changing Delivery Time & 0.096 & 0.162 & 2 \\
\hline \hline
\end{tabular}

TABLE 11.

THE PRIORITY WeIGHT OF WARRANTY \& ClaIM POLICIES SUB-CRITERIA

\begin{tabular}{lccc}
\hline \hline \multirow{2}{*}{ Warranty \& Claim Policies sub-criteria } & \multicolumn{2}{c}{ Weight } & \multirow{2}{*}{ Priority } \\
\cline { 2 - 3 } & Lower & Upper & \\
\hline $\begin{array}{l}\text { Providing a warranty or guarantee for } \\
\text { goods }\end{array}$ & 0.169 & 0.272 & 1 \\
$\begin{array}{l}\text { Ability to Provide Assistance in an } \\
\text { Emergency }\end{array}$ & 0.037 & 0.060 & 2 \\
\hline \hline
\end{tabular}

TABLE 12.

THE PRIORITY WEIGHT OF PERFORMANCE HISTORY SUB-CRITERIA

\begin{tabular}{cccc}
\hline \hline \multirow{2}{*}{ Performance History sub-criteria } & \multicolumn{2}{c}{ Weight } & \multirow{2}{*}{ Priority } \\
\cline { 2 - 3 } & Lower & Upper & \\
\hline Ability to fulfill determined schedules & 0.076 & 0.179 & 1 \\
Ability to fulfill in number of orders & 0.071 & 0.186 & 2 \\
Ability to maintain contract agreements & 0.033 & 0.084 & 3 \\
\hline \hline
\end{tabular}

TABLE 13.

THE PRIORITY WEIGHT OF COMMUNICATION SYSTEM SUB-CRITERIA

\begin{tabular}{|c|c|c|c|}
\hline \multirow{2}{*}{ Communication System sub-criteria } & \multicolumn{2}{|c|}{ Weight } & \multirow{2}{*}{ Priority } \\
\hline & Lower & Upper & \\
\hline onsistency level for information exchange & 0.067 & 0.110 & 1 \\
\hline Types of used communication & 0.018 & 0.030 & 2 \\
\hline
\end{tabular}

TABLE 14

THE PRIORITY WeIght OF MANAGEMENT \& ORGANIZATION SUBCRITERIA

\begin{tabular}{cccc}
\hline \hline \multirow{2}{*}{ Management \& Organization sub-criteria } & \multicolumn{2}{c}{ Weight } & \multirow{2}{*}{ Priority } \\
\cline { 2 - 3 } & Lower & Upper & \\
\hline Completeness of goods offer document & 0.047 & 0.085 & 1 \\
Completeness of company documents & 0.012 & 0.021 & 2 \\
\hline \hline
\end{tabular}

TABLE 15. CONSISTENCY RATIO

\begin{tabular}{|c|c|c|c|c|c|c|}
\hline \multirow{3}{*}{$\begin{array}{c}\text { Criteria and Sub- } \\
\text { Criteria }\end{array}$} & \multicolumn{6}{|c|}{ Respondent } \\
\hline & \multicolumn{2}{|c|}{ Respondent 1} & \multicolumn{2}{|c|}{ Respondent 2} & \multicolumn{2}{|c|}{ Respondent 3} \\
\hline & CR-K & CR-SK & CR-K & CR-SK & CR-K & CR-SK \\
\hline Cost & 0.098 & & 0.089 & & 0.063 & \\
\hline \multicolumn{7}{|l|}{ Delivery } \\
\hline $\begin{array}{lr}\text { Time, } & \text { Transportation } \\
\text { Costs, } & \text { Delivery } \\
\text { Frequency, Type of } \\
\text { Transportation Mode, } \\
\text { Shipping Amount. }\end{array}$ & & 0.050 & & 0.050 & & 0.075 \\
\hline \multicolumn{7}{|l|}{ Quality } \\
\hline $\begin{array}{l}\text { Completeness of } \\
\text { Checking Documents, } \\
\text { Defect Rate, Ability } \\
\text { to Provide Consistent } \\
\text { Quality }\end{array}$ & & 0.048 & & 0.048 & & 0.008 \\
\hline
\end{tabular}

\section{Performance History}

Ability to fulfill in

0.074

0.027

0.016

number of orders,

Ability to maintain

contract agreements,

Ability to fulfill

determined schedules

TABLE 16

SAND SUPPLIERS RANKING

\begin{tabular}{cccc}
\hline \hline \multirow{2}{*}{ Sand Supplier } & \multicolumn{2}{c}{ The Value of Rough VIKOR Index } & \\
\cline { 2 - 3 } & QL & Qunking \\
P1 & 0.343 & 1.000 & 3 \\
P2 & 0.050 & 0.487 & 2 \\
P3 & 0.000 & 0.338 & 1 \\
\hline \hline
\end{tabular}


The $1^{\text {st }}$ International Conference on Business and Management of Technology (IConBMT)

August 3rd 2019, Institut Teknologi Sepuluh Nopember, Surabaya, Indonesia

TABLE 17.

CORAL SUPPLIERS RANKING

\begin{tabular}{cccc}
\hline \hline \multirow{2}{*}{ Coral Supplier } & \multicolumn{2}{c}{ The Value of Rough VIKOR Index } & \\
\cline { 2 - 3 } & QL & QU & \\
\hline K1 & 0.402 & 1.000 & 3 \\
K2 & 0.089 & 0.397 & 2 \\
K3 & 0.000 & 0.299 & 1 \\
\hline \hline
\end{tabular}

\section{REFERENCES}

[1] A. Amid, S. H. Ghodsypour, and C. O’Brien, “A weighted maxmin model for fuzzy multi-objective supplier selection in a supply chain," Int. J. Prod. Econ., vol. 131, no. 1, pp. 139-145, 2011.

[2] C. Gencer and D. Gürpinar, "Analytic network process in supplier selection: A case study in an electronic firm," Appl. Math. Model., vol. 31, no. 11, pp. 2475-2486, 2007.

[3] K. Shahroudi and S. M. S. Tonekaboni, "Application of TOPSIS method to supplier selection in Iran auto supply chain," J. Glob. Strateg. Manag., vol. 6, no. 2, pp. 123-131, 2012.

[4] B. Chang, C. W. Chang, and C. H. Wu, "Fuzzy DEMATEL method for developing supplier selection criteria," Expert Syst. Appl., vol. 38, no. 3, pp. 1850-1858, Mar. 2011.

[5] J. D. Huang and M. H. Hu, "Two-stage solution approach for supplier selection: A case study in a Taiwan automotive industry," Int. J. Comput. Integr. Manuf., vol. 26, no. 3, pp. 237-251, 2013.

[6] BPMIGAS, Pedoman Tata Kerja Pengelolaan Rantai Pasok Pengembangan Perumahan. BPMIGAS, 2011.

[7] E. Juarti, Kajian Pola Rantai Pasok Pembangunan Perumahan. Bandung: Institut Teknologi Bandung, 2008.

[8] L. Y. Zhai, L. P. Khoo, and Z. W. Zhong, "A rough set based QFD approach to the management of imprecise design information in product development," Adv. Eng. Informatics, vol. 23, no. 2, pp. 222-228, Apr. 2009.
[9] L. Y. Zhai, L. P. Khoo, and Z. W. Zhong, "A rough set enhanced fuzzy approach to quality function deployment," Int. J. Adv. Manuf. Technol., vol. 37, no. 5-6, pp. 613-624, May 2008.

[10] R. V. Rao, "Multiple Attribute Decision Making in the Manufacturing Environment," in Springer Series in Advanced Manufacturing, London, UK: Springer-Verlag London, 2013 pp. 1-5.

[11] S. Opricovic and G. H. Tzeng, "Compromise solution by MCDM methods: A comparative analysis of VIKOR and TOPSIS," Eur. J. Oper. Res., vol. 156, no. 2, pp. 445-455, Jul. 2004.

[12] A. Sanayei, S. Farid Mousavi, and A. Yazdankhah, "Group decision making process for supplier selection with VIKOR under fuzzy environment," Expert Syst. Appl., vol. 37, no. 1, pp. 24-30, Jan. 2010

[13] S. Opricovic and G. H. Tzeng, "Extended VIKOR method in comparison with outranking methods," Eur. J. Oper. Res., vol. 178, no. 2, pp. 514-529, Apr. 2007.

[14] A. Jahan, F. Mustapha, M. Y. Ismail, S. M. Sapuan, and M. Bahraminasab, "A comprehensive VIKOR method for material selection," Mater. Des., vol. 32, no. 3, pp. 1215-1221, Mar. 2011.

[15] K. Devi, "Extension of VIKOR method in intuitionistic fuzzy environment for robot selection," Expert Syst. Appl., vol. 38, no. 11, pp. 14163-14168, 2011.

[16] G. W. Dickson, "An analysis of vendor selection systems and decisions," J. Purch., vol. 2, no. 1, pp. 5-17, 1966.

[17] I. K. Wardhani, "Seleksi Supplier Bahan Baku Dengan Metode TOPSIS Fuzzy MADM (Studi Kasus: PT. Giri Sekar Kedaton Gresik )," Institut Teknologi Sepuluh Nopember, 2012.

[18] B. Muslim and Y. Iriani, "Pemilihan supplier bahan baku tinta menggunakan metode Analytical Hyrarchy Process (AHP) (Studi kasus di PT. INFIGO)," in Seminar Nasional Design and Application of Technology, 2010, pp. 19-26. 